\title{
DEMOCRATIZAÇÃO E UNIVERSALIZAÇÃO DA ESCOLA PÚBLICA: UM DIREITO DE TER DIREITO À DIVERSIDADE
}

\author{
Hélia Maria Matos Santos ${ }^{1}$
}

\section{RESUMO}

Este artigo é fruto de estudos de pesquisa relativa à temática científica educacional, intitula "Olhar de professor face à diversidade cultural no Ensino Fundamental". No tocante a este estudo, a presente pesquisa teve como objetivo analisar o olhar dos/as professores/as que atuam no ensino fundamental no desempenho da prática escolar, hoje identificada em grande expansão no cotidiano de sala de aula. É pertinente e necessário ampliar estudo e conhecimento com análise de concepções históricas a trajetória da educação pública brasileira ao processo de democratização do acesso dos/as alunos/as e a universalização que se discute para efetivar e atender a toda população em idade própria escolar, independente de condições social, étnica e cultural. Para a diversidade assistida, instituiu-se um direito de ter direito à educação pública de qualidade com garantia de aprendizado. Trabalhar a diversidade cultural dos/as alunos/as como um recurso de ensino significa estar sensível à possibilidade de que todos são iguais e que todos podem aprender. Este desafio encontra-se na possibilidade de despertar no professor/a o olhar não daltônico sensível, atento e heterogêneo, como as cores do arco-íris, representadas nas diferenças culturais e o modo de ser dos/as alunos/as, sentindo essas diferenças através dos vários olhares. Esta perspectiva conduziu a uma abordagem qualitativa descritiva, com levantamento de informações relativas à prática metodológica de quatro sujeitos pesquisados das escolas públicas e particular de ensino, que desenvolvem simultaneamente atividades práticas no $9^{\circ}$ ano do ensino fundamental. Utilizaram-se como instrumentos metodológicos a observação e a entrevista semiestruturada. Chegou-se à conclusão que os olhares dos/as professores/as revelam que, tanto as escolas pública e privada, refletem a diversidade cultural. O diferencial está na cobrança dos pais, na disponibilidade de recursos didáticos necessários à prática metodológica diversificada aplicada no processo de ensino. Acreditamos que a diversidade cultural é salutar ao desenvolvimento do conhecimento dos docentes e discentes. O perfil metodológico dos/as professores/as traduz concepções relativas à própria formação educativa e profissional, a partir da estrutura da oferta focada entre o real e o ideal frente à diversa demanda assistida e presente no âmbito da sala de aula.

Palavras-chave: Diversidade Cultural. Prática Docente. Ensino Fundamental.

${ }^{1}$ Mestre em Ciências da Educação pela Universidade Lusófona de Humanidades e Tecnologias de Lisboa/Portugal. Especialização em Gestão Escolar pela FANESE. Especialização em Administração e Supervisão Escolar pela Faculdade Pio Décimo. Licenciada em Pedagogia pela mesma instituição. E-mail: heliamms@infonet.com.br 


\section{ABSTRACT}

This article is the result of studies and research on the scientific educational theme, entitled Teacher's look facing cultural diversity in the elementary school. With regard to this study, the present research aimed to analyze the look of tutors working in elementary school with practice performance, today identified in great expansion in the daily life of the classroom. Relevant and necessary to enhance study and knowledge to analyze historical conceptions of the trajectory of the Brazilian public education to the process of democratization of access of students and universalization that discusses how to commit and serve the whole population in school age, regardless of social, ethnic and cultural conditions. For assisted diversity it has been established a right to have the right to quality public education, guaranteeing learning. To develop the cultural diversity of the pupils as a source of teaching means being sensitive to the possibility that all of them are equal and can learn. On this purpose, the present study had as an aim the critical analysis by the teacher's view to the cultural diversity. This challenge is in the possibility of rousing in the teacher the sensitive, attentive and heterogeneous colorblind look, like the rainbow colors, represented in the diversities and the way the students are, feeling these differences through many looks. This perspective leaded to a descriptive qualitative approach, collecting information to the methodological practice of four students researched at public and private schools that develops simultaneously practical activities on the 9th grade. Observation and semi-structured interview were the methodological instruments used. It can be concluded that the teacher's looks reveal that both the public and private schools reflect the cultural diversity. The difference is on the parents' charge, availability of the necessary didactic sources and the diversified practice applied on the process of teaching. We believe that this diversity is beneficial to the development of the students and teachers' knowledge. The methodological profile of the teachers brings conceptions related to their professional and educative background from the structure of the offer focused between the real and the ideal front of diverse demand assisted and present within the classroom.

Keywords: Culture Diversity. Teacher Practice. Basic Education. 


\section{Introdução}

Este artigo tem sua gênese em reflexões e experiências desenvolvidas na elaboração do Projeto de Pesquisa do Curso de Pós-Graduação de Mestrado intitulado Olhar de Professor Face à Diversidade Cultural no Ensino Fundamental. Realizado em um estudo de caso, sob a ótica da democratização do acesso e expansão do ensino público, que traduz uma análise simultânea do ensino privado, e a prática de professor contextualizada por um espaço democrático, diverso e uma demanda multivariada. A pesquisa revelou que o problema da qualidade e da aprendizagem,

[...] não se estabelece apenas nos seus alunos e em suas condições culturais, mas também da sensibilidade, da apropriação do real e do entendimento dos mecanismos dos sistemas educacionais, e da formação acadêmica adequada dos professores (SANTOS, 2008, p. 162).

Grande foi o ganho de conhecimento adquirido, o qual, na perspectiva atual, pontua esta temática.

Ao abordar a temática, faz-se necessário voltar o olhar para um breve histórico da escola pública brasileira. Seu acesso restrito, até a década de 1950, atendia a uma minoria privilegiada, consequentemente, é marca determinante da exclusão e discriminação dos menos favorecidos, segregado por fatores político, sociocultural, econômico e étnico-racial. Tal fato deixou a herança do atraso em desenvolvimento educacional. $\mathrm{O}$ acesso democrático, em oposição à escola restrita a poucos, teve inicio com as reivindicações dos educadores da Escola Nova a partir da década de 1930, se configurou em meado do século XX, e se intensificou na década de 1980 - década da Constituição brasileira.

Decorrente da democratização da escola pública, surgiu a massificação do ensino público brasileiro, antes mesmo da atual Constituição Federal Brasileira de 1988, porém, não registrou bons rendimentos - a repetência e a evasão cresciam a cada ano, principalmente nas $1^{\mathrm{a}}$ e $2^{\mathrm{a}}$ séries da Educação Básica; isso elevou o número de pessoas sem lograr êxito a abandonar a escola. Buscaram-se então ações alternativas a solução do problema na pré-escola, mas as ações precisavam de uma articulação política de orientação do crescimento 
quantitativo, em garantir recursos materiais e preparar os recursos humanos para um funcionamento eficaz.

Isso levou e leva até hoje estudiosos e pesquisadores a debater sobre o tema, os profissionais da educação, que visam a discutir e conceber uma educação para todos, e a favorecer a democratização do acesso e a universalização do ensino a crianças, jovens e adultos de todos os segmentos e classes sociais. Mas os dados revelam que a democratização do ensino parece distante de atingir cem por cento da população em idade própria escolar, menos ainda, sua universalização. "O Brasil ainda tem $8 \%$ de suas crianças e adolescentes fora da escola, na faixa de 4 a 17 anos, o que representa algo como 3,2 milhões de crianças". (CRUZ, 2013, p.36). Antes mesmo de vencer o desafio da universalização as políticas devem também colocar de frente outros desafios, os quais ainda pairam sobre o ensino público brasileiro, por exemplo, o problema da baixa eficiência do sistema, as elevadas taxas de abandono, a evasão, a repetência e a má qualidade do ensino. Essa instituição, atualmente, possibilita ao aluno de classe sociocultural de baixo poder aquisitivo o direito ao acesso e à frequência institucional. Porém, a visão do sistema educativo brasileiro hoje ainda é ofertar situação de oportunidade através do acesso aos alunos de diferentes grupos sociais, mas não se entende igualdade de oportunidade para grupos diferentes e heterogêneos apenas pelo fato do acesso à escola e menos ainda pelo tratamento idêntico a pessoas diferentes.

Aparentemente se articulou herculeamente um acesso verticalizado do governo para os diversos grupos sociais menos favorecidos sem que os mesmos estivessem em condições de usufruir disto. Por exemplo, como crianças que trabalhavam poderiam se manter nesse ambiente? Só bem depois a Organização Internacional do Trabalho e a Organização das Nações Unidas exigiram a erradicação do trabalho infantil, do qual surgiram programas como o PETI - Programa de Erradicação do Trabalho Infantil.

Nesse esteio, de acordo com a Declaração Mundial sobre a Educação para Todos (UNESCO, 1990), procurou-se desfazer a visibilidade de acesso à escola como equivalência à universalização da educação, através de encontro avaliativo, quase uma década depois. Mas a ênfase continuou na democratização do acesso, com medidas voltadas à permanência do aluno para concluir o ciclo escolar, na lógica de primazia da quantidade (e números para as agências de fomento) e, 
secundariamente, da qualidade. Destarte, sendo a lógica primeira favorável ao acesso à escola, supostamente a aprendizagem viria como consequência, entretanto observou-se a atenção ao acesso, à quantidade e não à qualidade do ensino.

Universalizar a educação básica continua sendo entendida também, fundamentalmente, como universalizar o acesso à escola. A intensa expansão de massa na educação para todos, nas últimas décadas do ensino fundamental, provocou mudanças na composição da demanda de alunos e professores nas instituições públicas escolares, ou seja, incorporou ao progressivo setor uma situação cada vez mais heterogênea da população, com amplo segmento da classe popular.

A escola pública, notadamente no ensino fundamental, "tem evoluído no sentido de se apresentar como local de encontro de todos os setores da população e campo de repercussão das tensões conturbadoras da vida coletiva na sociedade moderna" (TEDESCO, 2001, p. 36). A evolução que descreve o autor deixou o professor consciente da necessidade de uma estrutura de dominação, num tipo social diverso, mais complexo, transformado em profissional diante de muita alternativa teórica e política. $\mathrm{O}$ aluno, recrutado em todos os estratos populacionais, aparece no interior da escola como portador de representação da existência sociocultural e do reflexo de diferentes segmentos da sociedade. Faz-se necessário compreender a possibilidade de reelaboração coletiva dessa multiplicidade de representação e vivência que varia bastante.

Sendo assim, há necessidade de uma política educacional, respaldada no respeito ao outro, à diversidade cultural, étnico-racial e humana dos alunos, além da possibilidade de aprenderem juntos, livre de qualquer condição negativa de aceitação ou discriminação.

De acordo com (CORTESÃO, 2002, p. 65), juntamente com o grau de dificuldade, "surgiram também orientações educativas no sentido de que se trabalhem numa atmosfera de maior respeito e aceitação da diferença". A autora faz referência à sensibilidade, à atenção, à heterogeneidade e ao "arco-íris" das culturas, o qual designou em trabalho anterior como professor "não daltônico".

Para os autores (CORTESÃO; STOER, 1996, p. 53), “o daltonismo cultural leva a escola a enxergar os alunos em tons cinzentos, em 
grupos/turmas homogêneas, dificultando o valor do diferente, do diálogo autêntico". O olhar daltônico constitui impedimento para a diferença, à visão é única, com tratamento igual à pessoa diferente.

A escola e o professor não daltônico traduzem sensibilidade na percepção de seus olhares, vê e observa as cores refletidas pela diversidade cultural, social, étnica, econômica e de ritmo de aprendizagem pela heterogeneidade. Dessa maneira, o importante é que o acesso ocorra considerando a real necessidade básica de sucesso da aprendizagem de todos os alunos e que eles desenvolvam plenamente a capacidade de participar do processo local e global da sociedade, melhorar a qualidade de vida e continuar a aprender.

Neste sentido, infere a um dos pontos mais altos da política educacional, o direito à diversidade, o direito de ter direito ao sucesso na aprendizagem, expresso no direito de inclusão de todas as crianças aprenderem juntas, independente de suas condições pessoais, sociais ou culturais. Trata-se de um modelo de escola sem exigência de acesso, sem mecanismo de seleção ou discriminação de qualquer espécie. O princípio de inclusão da UNESCO (1994), é que as escolas e os sistemas de ensino regular devem "acomodar todas as crianças independentemente de suas condições físicas, intelectuais, sociais, econômicas, linguísticas ou outras." Tais condições geram uma gama de desafios aos sistemas educacionais.

Estes desafios não isentam a existência de diferente visão neste campo, seja no intuito de adotar a perspectiva de educação para todos, que enfatiza a relevância da diversidade cultural como elemento enriquecedor da aprendizagem, ou para se criarem condições de desenvolvimento, com garantia de educação de qualidade e equidade, implicadas na transformação dos sistemas e nas políticas educacionais.

O desafio está em conhecer e reconhecer as diferenças, a diversidade de características, capacidades e motivações de seus alunos, responder às necessidades educacionais de cada um, para que todos progridam no seu aprender e participem do processo em igualdade de condições, beneficiando-se através de um ensino adaptado e voltado às suas necessidades.

Este estudo tinha como objetivo analisar o olhar de professores que atuam no ensino fundamental face à diversidade cultural através de um 
estudo de caso. Teve como objeto de estudo o professor e a diversidade cultural presente no âmbito escolar. Em resposta ao objetivo geral, traçaram-se os objetivos específicos para conduzir à conclusão final do processo investigatório, que foram: associar a prática do professor com a diversidade cultural e as diretrizes pedagógicas escolares do ensino fundamental, identificar a escola como espaço integrante da diversidade cultural e analisar a interação entre conhecimento científico desenvolvido em sala de aula, metodologia didática e aspecto sociocultural dos alunos.

Para melhor conduzir este estudo investigativo, foi formulada a seguinte problemática: os professores no desempenho de suas funções pedagógicas olham a diversidade cultural como um problema ou como instrumento de enriquecimento para a aprendizagem dos alunos?

Assim, o universo e a abrangência desse estudo se pautaram na prática de sala de aula dos professores que atuam simultaneamente em 03 (três) escolas com as disciplinas de Matemática, Física, História, Língua Estrangeira/Inglês e Língua Portuguesa. Duas escolas da rede pública - uma estadual e uma municipal - e uma escola particular localizadas no município de Japaratuba-SE, onde se coletaram dados necessários à presente investigação.

Tratou-se do uso de amostra não aleatória e intencional que teve como sujeitos da pesquisa quatro professores que trabalham simultaneamente no $9^{\mathrm{a}}$ ano da Educação Básica, observados e entrevistados. A escolha dos mesmos foi feita com base na formação. Os procedimentos metodológicos de investigação da pesquisa qualitativa serviram ao estudo para levantamento de dados.

Utilizou-se também da técnica de observação participativa, sistemática planejada, individual e de campo, considerou-se os objetivos propostos na utilização de registro em fichas previamente elaboradas, como também fez-se necessário o uso de entrevistas não diretivas.

Organiza-se, ainda, esse estudo em uma discussão acerca da educação pública brasileira, sua democratização, sua universalização e sua diversidade e, a partir de tais pressupostos, se contextualizarem resultados e considerações finais. 
Este artigo está dividido em sete partes, sendo a última sobre as considerações finais e a penúltima uma sucinta análise de dados. A primeira parte versará sobre as nuances da educação pública brasileira, contextualizando-a sócio-historicamente; as demais, sobre a democratização, universalização, diversidade na escola e um direito a essa diversidade.

\section{Educação pública brasileira}

A atual concepção da educação pública brasileira nos leva a uma breve análise sobre os avanços e recuos relativos ao sistema educacional brasileiro, a sociedade, os valores, os modelos impostos, seus princípios educacionais e as práticas que se efetivam na construção um ou de outro modelo, o qual a história escreve a cada tempo e época como bem ressalta Freire:

A sociedade impõe seus modelos educativos como elementos de estabilidade do sistema social e que nunca irá modificá-los voluntariamente num sentido que contradiga os seus interesses. Ao mesmo tempo o educador consciente sabe da importância que tem para a mudança social o modo como às pessoas percebem a realidade e a si mesmas. As pessoas que, mediante uma educação libertadora, descobrem o mundo e sua posição nele com consciência crítica, são os melhores sujeitos ativos de uma transformação séria e profunda das estruturas sociais. (FREIRE, 1987, p. 73):

$\mathrm{Na}$ sociedade ocidental, o sistema de educação, considerado tradicional, teve sua origem no final do século XIX, respondendo às exigências do processo de construção da democracia para os Estados Nacionais e às exigências econômicas de mercado da época. Houve, por conseguinte, uma expansão de estratégia relativa à criação de articulação que correspondesse à estrutura de sequência, servindo de organização à atividade escolar. São categorias que eram intimamente ligadas ao próprio modelo tradicional de escola para classificar os alunos considerados bons e excluir os ditos ruins. Isso ocorria a partir de um parâmetro: as escolas e a aprendizagem encontravam-se no centro do processo educacional de ensino, sem considerações dos níveis e dificuldades, constituídos pelos esforços dos alunos "menos capazes", até o momento em que estes educandos permutavam para a condição ou não de alunos "capazes”. 
Esse fato foi o que caracterizou o processo de exclusão escolar, de repetência e de evasão, denominado, na atualidade, por alguns estudiosos de "cultura da repetência" que tanto aflige a qualidade do ensino das escolas públicas brasileiras. Em sequência, sempre se esteve associada à própria capacidade ou não de desenvolvimento dos sujeitos e à hierarquia das posições sociais. Essas características, apesar de parecerem obvias, não pode ser comparadas à expansão e à universalização dos sistemas educacionais existentes em nossa atual realidade.

No que concerne ao sistema de educação tradicional, averígua-se uma crise manifestada por conta da impossibilidade de manter em vigor as categorias construídas; por este motivo, colocou-se em xeque a sequência clássica do acesso escolar ao conhecimento, aliado à necessidade de aprendizagem e formação permanente das pessoas. A hierarquização do acesso universal fez, por conseguinte, uma ruptura dos vínculos de autoridade no processo dissociado entre a ascensão educacional e ascensão social. A relação da ascensão na escola e da hierarquia educacional implicava:

Uma ascensão na hierarquia social, e o sistema educacional foi, dessa forma, o legitimador da mobilidade social existente. Essas características permitiram que a atividade educacional fosse percebida e conceitualizada em termos da ordem social dominante. Os conteúdos dos manuais escolares e das práticas pedagógicas, assim como a arquitetura geral do sistema educativo respondia a necessidade de garantir a ordem social pela adesão às normas dominantes (TEDESCO, 2001, p. 27).

Reportando-se à história da escola pública obrigatória, pode-se ressalvar o fato de a mesma ter sido projetada como instituição que concorria e ocupava um espaço tradicionalmente pertencente aos agentes socializantes: a família e a igreja. Por esta razão, no século XIX, a escola representava para a sociedade da época a continuação da família, principalmente no tocante à socialização moral e aos estilos de vida. Contraditoriamente, a escola agia objetivada para transformar a criança de acordo com os aspectos direcionados ao fortalecimento da coesão social da disciplina ${ }^{2}$ e, principalmente, aos códigos de conduta.

\footnotetext{
${ }^{2}$ Refere-se ao comportamento dos indivíduos adequados ou não conforme modelos e normas estabelecidos por determinada classe social seguido ideologicamente nas organizações e instituições de ensino.
} 
Nesse contexto, o processo educativo levava a criança a passar de uma instituição de coesão, a família, para outra, a escola; embora, a rigor, estruturada de maneira similar em sequência e hierarquia, as quais determinavam o modelo dominante definido por uma estrutura de base estabelecida por graus e etapas.

No século XX, a família passou a sofrer uma série de modificações bem maiores que a escola. Entre a instituição familiar do século XXI e a do final do século XIX, existe uma grande distância em relação a instituição escolar do século XXI e a do final do século XIX, por esta última apresentar menos mudanças. Isso ocorreu porque a família soube estabelecer diferenciação de respeito à diversidade, ampliando espaços de escolhas e personalização.

$\mathrm{Na}$ escola, a continuidade permaneceu mantendo a indiferença com opções reduzidas e resistentes à diversidade pessoal, social e cultural. O comportamento rígido da escola não significa que ela continuasse sendo orientada com base nos valores de classes identificados pela mesma mística e o mesmo entusiasmo perceptível pelos educadores do começo do século passado. Porém, a manutenção dos traços clássicos transformou-se em pura formalidade, com base no funcionamento burocrático, que apenas faz com que debilite ainda mais a autoridade e a legitimidade da mensagem socializadora da escola. Nesse esteio:

Na escola pública atual, essa opção ainda é observada por seus alunos, impulsionados pelo fracasso da aprendizagem cada vez mais presente no espaço escolar, e sem conseguir aprender os conteúdos apresentados metodologicamente como um único modelo, ou ainda mediante a violência e a conduta de marginalidade social provocada pela indiferença e mínima dedicação de esforços ao trabalho escolar público (TEDESCO, 2001, p. 37).

A crise do modelo educacional tradicional apresenta como base as categorias de sequência e hierarquia. Tal fato mostra que o problema da educação está no aspecto qualitativo. Visto que no modelo tradicional, qualidade e quantidade tinham um vínculo direto e linear nos níveis mais altos de complexidade qualitativa e estavam associados à menor quantidade de indivíduos com acesso à escola pública. Esse vínculo direto e linear resiste à nova realidade, uma vez que a expansão do acesso à escola pública rompeu o equilíbrio tradicional em relação à hierarquia social. Com a massificação da 
escola pública, houve uma quebra da relação entre nível educacional e posto de trabalho.

A atual situação passou a se apresentar com inversão de valores, a quantidade intimidou a qualidade, vista na tradicional escola apenas para poucos. Pensar na escola pública brasileira de hoje, significa pensar também que a escola e sua prática precisam ser revistas, diante das evidências, do mesmo modo que o direcionamento nos coloca entre qualidade e quantidade do serviço público educacional.

Em relação ao enunciado anteriormente, Tedesco assevera que "o que se ensina e quem deve aprender são, em consequência, duas questões para formar um só bloco de problema" (2001, p. 43). O histórico da educação se constitui em uma rica fonte de ensinamentos acerca dos padrões que regularam, durante várias décadas, a relação entre quantidade e qualidade. Essa oposição gira em torno de tendências educacionais antidemocráticas no sentido de reabilitar mecanismos de ajuste e a solução se dá a partir da seletividade, em função de tendências democráticas apoiadas na universalização do acesso ao conhecimento.

A educação, que vem sendo utilizada pela classe dominante para transmitir sua hierarquia de valores, não é, e não tem por que ser em si mesma opressora. Ela se torna um veículo de opressão dentro de estruturas sociais opressoras. Dentro dessas estruturas, surge o ato educativo como um depósito de conteúdos que o professor faz no aluno, a partir de uma premissa inicial; o professor "possui" a cultura e o saber; o aluno "ignora" e, por isso necessita ser levado a esse saber (FREIRE, 1987, p. 37).

Neste sentido, a condição de oprimido se constitui na concepção do ato de educar, desenvolvida pela própria concepção do professor, a de opressor, quando este profissional se considera detentor do saber, e os alunos no processo de ensino, seres que nada sabem. O aluno deveria ser olhado de acordo com a perspectiva dialética, sujeito construtor de sua história de vida, através das suas experiências do dia-a-dia, até então destituídas de valores. No entanto, a prática, não deveria denotar que os alunos sejam direcionados a receberem passiva e acriticamente os conteúdos trabalhados em sala de aula. 


\section{Democratização da escola pública brasileira}

A educação e a sociedade brasileira iniciam um processo de democratização das oportunidades do ensino como elemento central nas mudanças a partir da década de 30. Assim, o antigo ensino estava sendo substituído por um novo sistema acessível à maioria da população. Isso ocorreu mediante o crescimento das matrículas nos vários níveis de ensino, especialmente no que se referia à formação comum dos habitantes com a mudança dos conteúdos e a formação do cidadão.

Em relação ao aspecto quantitativo, o processo de democratização das oportunidades teve grandes limitações uma vez que a escolaridade não teve um desenvolvimento homogêneo para todo o país; isto porque ocorreram grandes desigualdades no acesso em algumas regiões, visto que o sistema de ensino se aproximou apenas do ideal pedagógico de algumas escolas; em outras áreas, ou seja, em estados mais pobres, zonas rurais e periferias dos centros urbanos estiveram e continuam a estar ainda longe de absorver a totalidade da população escolarizável, principalmente no $1^{\circ}$ e $2^{\circ}$ ano da Educação Básica.

O sistema de estatísticas educacionais permite a análise das dificuldades encontradas no ensino que aponta um indicador expressivo para o fracasso escolar de grande parte da população e permite dentre as causas do escasso rendimento dos alunos que ingressam nos múltiplos aspectos de desencontro das escolas com a característica sociocultural de significativa parcela da população. Exemplo de um desencontro, o que exprime, dentre outras formas, conteúdos desvinculados dos estilos de vida das populações. Para Romanelli

A falta de mudanças significativas nas taxas de promoção, com sucessivos dados cumulativos do abandono escolar, é uma análise situacional da educação que aponta a evasão escolar como um dos principais indicadores (1978, p. 78).

Há também outras questões que interferem no rendimento escolar dos alunos, entre eles carência alimentar e, principalmente, a carência cultural, além do trabalho infantil.

A carência alimentar no período de gestação, em muitos casos continuando após o nascimento da criança, pode provocar 
retardamento mental com intensidade diversa ao aluno. Mas a análise em sentido estrito das consequências desastrosas de outra grande forma de subnutrição é a carência cultural, a qual estaria exposta as populações por eles consideradas subalternas. A ideia de uma carência de cultura é insustentável, mesmo com relação às populações mais rústicas ou atrasadas.

Qualquer tipo de carência significa ausência a ser consideravelmente inadequada ao ser humano, principalmente aos desprovidos de acesso ao desenvolvimento socioeconômico e cultural, mas a precariedade das formulações relativas à carência cultural do ponto de vista da escola é considerada um fenômeno apontado e apresentado como real.

Rendimento e deficiência do ensino primário, choques entre os segmentos das populações urbanas que resultavam fundamentalmente de choque cultural entre os conteúdos de ensino e as condições de vida econômica social e cultural das comunidades rurais e semiurbanas. Extraídos dos modos de vida e das culturas das camadas médias e superiores das áreas urbanas, o conteúdo da escola primária entraria em choque com os estilos de vida das populações ainda não urbanizadas. (PEREIRA, 1971, p. 179).

Ainda de acordo com o autor, amplos segmentos da população subalterna, sobretudo nas zonas rurais e nas periferias das áreas urbanas, vivem em meio a uma cultura geral ausente dos conteúdos e da organização do processo educativo, que não a valoriza, que não a aceita e não a leva em consideração. Por mais complexos e adaptativos que sejam esses contextos culturais, eles estão excluídos da escolaridade. Assim, do ponto de vista de uma cultura dominante que define as orientações e os conteúdos da escolaridade, essas populações, de fato, são "carentes" e a "carência" é considerada a dificuldade na assimilação dos conteúdos da cultura, se exprimindo sob a forma de deficiência de rendimento na escola.

Outro fator considerado extraeducacional ao precário rendimento do ensino, é a necessidade de trabalho do menor nas famílias de baixa renda, das áreas rurais nas épocas de plantio e colheita, como também nas grandes cidades pela exigência da subsistência que impõe o trabalho para todos os membros da família considerados úteis por viabilizarem qualquer tipo ou subtipo de renda para a comunidade familiar, conforme mencionado na introdução. 
São várias as relações das expressões na determinação social do fracasso escolar das populações desfavoráveis, mas sob o ponto de vista das características da demanda, o rendimento da escolaridade pode variar. Observou-se que as melhores escolas atendem às populações privilegiadas e as escolas carentes atendem às populações desfavorecidas.

Ao analisar a característica sociocultural e a diversidade dos alunos, Cunha

\footnotetext{
Os fatores restritivos à procura da escola, mesmo quando elas são acessíveis e os fatores restritivos ao bom rendimento escolar e a permanência nos cursos estariam estreitamente associados á situação de classe das populações desfavoráveis (CUNHA, 1970, p. 150).
}

As informações arroladas pelo autor indicam que as taxas mais elevadas de escolarização correspondem aos estados de maiores rendas. Ficando, assim, os piores índices nas áreas rurais por apresentarem um número reduzido de escolas e pela migração sistemática dos trabalhadores e suas famílias, além da existência de incompatibilidade entre o ano agrícola e o ano escolar, bem como da ênfase maior dada à escolarização urbana em termos políticos eleitorais.

\section{Universalização da escola pública brasileira}

A rede regular de ensino buscou utilizar recursos para expandir e priorizar as séries iniciais do ensino fundamental; no entanto, em fins da década de 1980, havia grande necessidade de pretensão que garantisse, de fato, as liberdades democráticas. Surgiu a necessidade de um governo de aspiração para uma real democracia institucional e social no Brasil, que priorizasse a educação do ensino fundamental e pusesse em prática a universalização do ensino, ou seja, do ensino formal regular concentrado por recursos e poder de coordenação nos órgãos da administração direta, para ser desenvolvido nas esferas federal, estadual e municipal. Garantia de crescimento não só quantitativo, mas direcionado para uma melhoria qualitativa nas redes de escolas públicas obrigatórias e gratuitas: 
Universalizar o $1^{\circ}$ grau garantindo acesso e permanência a todos é um objetivo tão gigantesco quanto conciso. Não é tarefa para um governo apenas, talvez não seja para uma geração, mas as condições e início desse processo podem e devem ser desencadeados desde já. As estratégias a serem favorecidas são as que puderem gerar mudanças substanciais e consolidá-las, tendo em vista futuros avanços na direção de um ensino de $1^{\circ}$ grau de boa qualidade e para todos. (MELLO, 1987, p. 21).

A ideia de universalizar o ensino fundamental apresentou um prérequisito indispensável a sua efetivação, à escolaridade básica através de uma política educacional lúcida, realista, direcionada aos esforços financeiros para o essencial e para as condições futuras sólidas e passíveis de avanços. O objetivo destas medidas era permitir que a expansão das oportunidades educativas se traduzisse em desenvolvimento significativo, ou seja, que cada pessoa realmente aprendesse, adquirisse conhecimentos úteis, capacidade de raciocínio, aptidões e valores, centrando na educação, na aquisição e nos resultados efetivos de aprendizagem.

Por conseguinte, foi necessário adotar enfoques ativos e participativos na tentativa de garantir aprendizagem e permitir aos alunos desenvolvimento do seu potencial no decorrer deste processo. Para isso, tornou-se evidente definir níveis aceitáveis às referidas práticas através de programas educativos, melhorarias e aplicações sistemáticas de avaliação de resultados de aprendizagem. Esses níveis de rendimento deveriam ser coerentes com a prioridade da educação relacionada à universalização do acesso, com a aquisição da aprendizagem.

Outro fator observado e analisado nesse período foi a igualdade de gêneros dos meninos e meninas no campo educativo, que permaneceu vinculada ao acesso, sem muita expectativa e tratamento diferenciado dentro da instituição escolar, mas os indicadores de análise para meninas e meninos em seus rendimentos quanto à repetência por gênero demonstraram realidades imprevistas de discriminação dos homens concernente à escolaridade com baixo rendimento escolar além de maiores índices de evasão. Todos estes fatores levaram à busca por uma igualdade de gênero de maneira mais integral.

No Brasil, existe um perturbador fenômeno de inversão na exclusão de gênero, pois é as crianças e adolescentes do sexo 
masculino que abandonam primeiro a escola. Isto ocorre provavelmente devido à necessidade destes jovens buscarem meios para complementar a renda familiar. (TORRES, 2001, p. $64)$.

Esse fator retira crianças em idade escolar das escolas fazendo-as abandonarem os estudos tornando a frequência irregular, comprometendo assim a aprendizagem.

Nesse sentido, entra o papel da família, sendo necessário que essa instituição valorize mais a educação, incentivando e acompanhando a vida escolar dos filhos. A participação da família foi pontuada e analisada a partir dos relatos dos professores, na pesquisa, que o maior diferencial da escola privada é o acompanhamento dos pais, eles participam efetivamente, colaborando também, com a escola para melhoria do rendimento acadêmico como resultados ao êxito de seus filhos.

\section{Diversidade na escola para todos}

No intuito da existência de oportunidade educacional para todos, observou-se uma melhoria no sistema escolar. É inegável a persistência administrativa orientada para suavizar a expressão das desigualdades sociais para o âmbito da educação escolar; no entanto, no Brasil, as alterações não têm sido muito significativas.

As possibilidades de desenvolvimento de igualdade de oportunidades na educação em que a escola coloca em questão os fundamentos não igualitários da sociedade de classes se apresentam como forma de resistência às mudanças perceptíveis ao longo dos tempos em relação à diversificada e atual demanda no sistema de ensino.

No passado, a exclusão escolar das populações subalternas aparecia de forma simples e direta sob a inexistência de possibilidades de acesso aos setores decisivos do ensino. Hoje, o processo de exclusão continua presente de maneira menos disfarçada e menos transparente, apesar da generalização das oportunidades de acesso à escola para todos, disfarçada pela persistência e pelos mecanismos de discriminação e preconceitos. 
Quando há possibilidade real de ingresso ao ensino, progressivamente, surge a eliminação ou o enfraquecimento de algum aluno pela dificuldade encontrada para seguir os estudos. Os implícitos mecanismos não são tão evidentes, mas ao mesmo tempo, não é difícil perceber que a grande maioria de ingresso no ensino comum é excluída paulatinamente, no primeiro momento da vida escolar. Ressalve-se que a exclusão é persistente durante todo o processo de escolarização, sobretudo pela situação social, cultural e econômica do aluno.

Quanto à dificuldade por falta de clara percepção da permanência das desigualdades sociais na educação, as mudanças estão emprestando apenas formas de legitimidade disfarçada através de afirmação de existência de uma sociedade aberta à igualdade. Esta só pode ser real quando existe possibilidade de pleno desenvolvimento da potencialidade individual assegurada pela igualdade de oportunidade do aproveitamento do serviço de educação, pelo menos, para a maioria dos alunos.

É viável o alargamento de oportunidades oferecidas pelos sistemas educacionais com reforço da ideia de desenvolvimento de uma real democratização na sociedade, ou seja, de oportunidade escolar e transformação formal do sistema de ensino.

Concernente à extensão do ensino, a coletividade se apresenta como elemento constitutivo e como processo de instrumento de inculcação da realidade representada; portanto, como se pode perceber, a ampliação das oportunidades leva apenas à ampliação da ação ideológica desenvolvida pelo sistema escolar. A ação pedagógica não se esgota no processo de inculcação ideológica; a escolaridade envolve outra dimensão, principalmente, o aprendizado, como também o domínio de informação e desenvolvimento de habilidade.

A inculcação está situada no interior das transformações das experiências adquiridas e na formação das habilidades presentes no conhecimento ao transmitir técnicas de comunicação no decorrer do processo de desenvolvimento aos alunos. Desse modo, a escola transmite e desenvolve, simultaneamente, atitudes, sentimentos e valores expressos mediante a consideração de determinadas representações da existência social. O aprendizado das técnicas e o 
desenvolvimento das habilidades têm consequências específicas tais que:

\begin{abstract}
Inegavelmente implicam vantagens reais para a população escolar. Tanto é assim que a expansão das oportunidades escolares possibilitou a mobilidade social vertical em magnitudes variáveis, para grandes contingentes das populações urbanas. E mesmo que esta ascensão somente apareça sob a forma de ganhos individuais e não afete os fundamentos estruturais da sociedade de classes, para os indivíduos alcançados, e eles são muito numerosos, os benefícios obtidos são indiscutíveis. (TEDESCO, 2001, p. 36).
\end{abstract}

$\mathrm{O}$ atual contexto do sistema de ensino já não comporta a pura e simples identificação da escolaridade ideológica a serviço de uma determinada ordenação da vida coletiva. A escola, ao lado de outras instituições envolvidas na formação de atitudes, sentimentos e conhecimentos, tem realmente uma grande parcela de contribuição no processo de inculcação ideológica; por conseguinte, sua atuação nesse processo é complexa, é contraditória; e, de modo algum, poderia justificar a oposição aos esforços comprometidos como maior democratização das oportunidades para todos.

$\mathrm{O}$ argumento considerado como atribuição de peso negativo à democratização das oportunidades ocorre devido ao fato de a democratização precisar se aperfeiçoar, principalmente, quando é considerado elemento consultivo do sistema de representações mistificadoras da realidade social. O reconhecimento da persistência de largas desigualdades na educação escolar conduz à negação da validade de uma política educacional verdadeiramente democratizadora.

Essa política, na retórica legitimadora da ordem social, contamina, destrói, prejudica a condição para todos, mas não desqualifica irremediavelmente o trabalho dos educadores e as conquistas populares na educação.

Não foi observado razoável desapreço voltado para suavizar as desigualdades sociais, mesmo que essas desigualdades não tenham sido ainda completamente eliminadas na escola ou pela escola, mantendo funções estabilizadoras da ordem social não igualitária. 
É necessário diagnosticar e submeter à crítica tanto as desigualdades que insistem em permanecer, quanto as distorções ideológicas comprometidas com sua manutenção no interior do sistema de ensino e, ao mesmo tempo, reconhecer e apoiar as orientações ideológicas comprometidas com a transformação no interior do sistema de ensino e simultaneamente reconhecer e apoiar as orientações democratizadora da política educacional.

Nas iniciativas à ampliação da rede de escolas, volta-se à reformulação das características não igualitárias internas ao ensino e nos procedimentos com finalidade de alterar, dentro da escola, os efeitos educacionais negativos de condições sociais, culturais e econômicas definidas fora da escola.

A estrutura não igualitária da sociedade de classes impõe limites às possibilidades de democratização nas diferentes áreas da vida social. Estes limites, porém, são flexíveis e podem ser ampliados mediante a prática democratizadora.

Alguns educadores procuravam descobrir procedimentos que pudessem estender a atuação do processo educativo à própria origem social dos desafios enfrentados. Esta perspectiva se encontrava, de alguma forma, presente na justificativa ao falar da campanha para a educação de adultos.

\footnotetext{
Ao instalar sua rede de escolas supletivas em todo território, entre outros objetivos a campanha procurava obter a valorização do ensino nas comunidades e promover a melhoria do próprio ensino infantil. $\mathrm{O}$ adulto provido de alguma instrução, em meio igualmente rude pode contribuir para transformá-lo, seja atuando no seio do lar sobre os filhos, seja nas suas relações mais externas, sobre toda comunidade. (BEISIEGEL, 2004, p. 413).
}

Essa adesão de movimentos difundidos numa linha de preocupações envolvendo vários programas cujo propósito estava precisamente voltado para o desempenho e o crescimento da educação popular brasileira, isso a partir da década de 1960. Ainda segundo o autor, participaram os seguintes movimentos: O Movimento de Educação de Base (MEB), Os Movimentos de Cultura Popular (MCPS), os Centros Populares de Cultura e o Programa Nacional de Alfabetização. 
Todos eles tinham em comum o objetivo de estender a atuação do processo educativo e as origens sociais das desigualdades que buscavam combater. Apesar da curta história do Programa Nacional de Alfabetização, o mesmo chegou a caracterizar a evolução desses trabalhos supracitados.

\section{Escola: um direito de ter direito à diversidade}

Identificar para incluir implica em minimizar barreiras antepostas à aprendizagem e à participação, maximizar recurso que opõe o processo. As barreiras podem estar determinadas em todo o aspecto e estrutura de um sistema, no centro educacional, na comunidade, na política local. Não apenas podem impedir o acesso ao estabelecimento de ensino, como também pode conter limitação no termo para participar.

Da educação inclusiva se infere o fator de que toda e qualquer criança de determinada comunidade pode aprender uma com as outras, juntas, independente da condição pessoal, social ou cultural. Trata aqui de modelo de escola que não há exigência para o acesso, nem mecanismo de seleção ou discriminação a qualquer espécie. De acordo com o princípio da inclusão, as escolas do sistema de ensino regular devem:

\footnotetext{
Incluir crianças com deficiência e as superdotadas, meninos e meninas de rua e crianças trabalhadoras, crianças de origem remota ou de populações nômades, crianças pertencentes a minorias linguísticas, étnicas ou culturais e crianças de outros grupos em desvantagens ou à margem da sociedade. Tais condições geram uma variedade de diferentes desafios aos sistemas educacionais. (UNESCO, 1994).
}

Para esse ideal de escola inclusiva, é importante requerer e consolidar através do sistema educacional a ação contínua e sintonizada por todos os segmentos da educação, sobretudo, no que se refere à formação do educador garantindo, assim, o desenvolvimento pleno e o exercício da cidadania.

A educação inclusiva, no seu imperativo de tornar realidade as normas contidas nas declarações e nos compromissos adotados nos países da América Latina, visou efetivo atendimento a todas as crianças, o 
direito à educação, à participação e à igualdade de oportunidades, bem como o desempenho dos atuais enfoques pedagógicos, resultantes, ao longo das últimas décadas, em importante mudança de conceito no campo educacional. A existência de diferentes visões neste campo no intuito de recuperar sua natureza e sua função ao adotar a perspectiva de educação para todos, a qual enfatiza a relevância da diversidade como elemento enriquecedor da aprendizagem, bem como o desempenho pessoal e social.

Expandir a educação básica e os atuais processos de reforma educacional na busca de melhoria da qualidade e equidade na educação faz persistir a desigualdade de oportunidade educacional. Ou seja, os avanços que não se fizeram acompanhar de resposta eficiente, por parte dos sistemas educacionais, refletem em diferenças social, econômica, geográfica, linguística, cultural e individual, que conduzem a um alto índice de analfabetismo funcional, de repetência, evasão escolar e exclusão.

Para criar condições de desenvolvimento de escola para todos, com garantia de educação de qualidade e equidade, implica transformar os sistemas e as políticas educacionais, a organização e o funcionamento das escolas, as atitudes, a prática docente, os níveis de relacionamento entre os diversos atores e, por fim, toda uma cultura educacional diferente. Neste sentido, o sistema escolar deve ser ajustado para atender e satisfazer as necessidades de todos os alunos.

O desafio está em saber avançar em direção a uma escola inclusiva ou compreensiva, que qualifique seus alunos e reconheça as diferenças individuais como valor a ser levado em conta no desenvolvimento e na materialização dos processos de ensino e de aprendizagem. Uma escola adaptada à diversidade de características, capacidades e motivações de seus alunos, no sentido de responder às necessidades educacionais de cada um, para que todos progridam na aprendizagem e participem do processo de igualdade de condições, beneficiando-se através de um ensino adaptado às suas necessidades. Consolidar a inclusão enquanto possibilidade de combate à exclusão por meio de formação de docentes preparados para responder à diversidade de estilos de aprendizagem na sala de aula representa sentido social, político e econômico. 


\section{Apresentação e discussão dos resultados}

A discussão geral das entrevistas semiestruturada revelou que a diversidade cultural é uma realidade presente no âmbito da sala de aula do ensino fundamental, vivenciada e considerada, tanto nas escolas públicas como na escola privada, essa apresenta o diferencial, a família acompanha o desempenho dos filhos. A diversidade não constitui um problema e sim um instrumento de enriquecimento para a aprendizagem aferida nos dados qualitativos quanto à importância da heterogeneidade e da história de vida dos alunos inseridos em uma sociedade também heterogênea e naturalmente diversificada. As dificuldades devem ser identificadas e tratadas ou utilizadas como instrumentos de conhecimento, do contrário, ninguém aprenderia.

A análise quantitativa feita a partir dos documentos das escolas tomadas como lócus da pesquisa reflete aspectos negativos da diversidade sociocultural expressa nos índices de reprovação e abandono. A análise dos dados qualitativos com referência às falas dos entrevistados denotou um significado expressivo para a investigação, uma vez que ela responde de maneira menos duvidosa às motivações que conduziram a realização deste estudo, principalmente a importância que adquiriu a diversidade cultural ao olhar dos professores das escolas públicas e particular. A análise geral da observação sistemática contribuiu para o cruzamento dos dados estabelecendo os pontos comuns entre as entrevistas e as observações.

Quanto às dificuldades levantadas, observou-se a falta de motivação dos alunos, fator justificado pelas ausências dos pais da escola pública, desníveis de conhecimento, presentes nas redes pública e particular de ensino. Metodologias diversificadas, sem posposta pedagógica de escola e sem recursos didáticos suficientes e necessários voltados para $\mathrm{o}$ atendimento à diversidade presente nas superlotações das salas de aula da rede pública, desfavorável padrão de qualidade em virtude das facilidades de promoção escolar, principalmente na rede estadual.

Em contrapartida, quanto aos pontos positivos levantados, esses estão associados ao aprendizado, pela vivência dos alunos, presentes no âmbito de sala de aula e o interesse dos que sonham ter vida melhor que a dos seus progenitores, principalmente os alunos de zona rural. A diversidade, neste sentido, não foi apresentada como problema, e sim salutar fator de enriquecimento em virtude da heterogeneidade, por ser 
natural e compreensível a presente realidade, mas exigente quanto ao preparo dos professores e de grande desafio de sensibilidade do trabalho pedagógico ao tratamento das diferenças e o alcance da equidade.

\section{Considerações finais}

Percebeu-se, no olhar dos professores face à diversidade cultural no ensino fundamental do município de Japaratuba-SE, o desempenho de valores e concepções relativas à formação pessoal, educacional e profissional presente por uma realidade que entende e considera: "como se ensina" desloca para "como o aluno, face à realidade de hoje, aprende". Olhar sensível este que dissocia da prática coletiva heterogênea representativa das diversas cores do "arco-íris" para práticas metodológico-mescladas. Olhar consciente não daltônico, prática consciente daltônico-real, observador-ideal que não se concretiza na prática de sala de aula.

Decerto existe uma falta de implementação de política escolar que defina uma prática coletiva, subsidie proposta curricular e projetos que reconheçam e valorizem a diversidade cultural no âmbito da sala de aula. Conceba o aluno como sujeito integral, de múltiplas dimensões, não o veja apenas como indivíduo que busca ou recebe informações, mas como sujeito que aprende, instrui e desenvolve o pensamento criativo, observa suas atitudes e relações com os diversos grupos.

\section{Referências}

BEISIEGEL, C. de R; Educação e Sociedade no Brasil após 1930. Cap. VII. In: FAUSTO, B. História geral da civilização brasileira: III. O Brasil Republicano, 4. Economia e cultura. (1930 - 1964). Rio de Janeiro: Bertand Brasil, 2004.

CORTESÃO, L; Ser professor: um ofício em extinção? Porto: Edições Afrontamento, 2002. 
CORTESÃO, L. \& STOER, S; A interculturalidade e a educação escolar. Inovação, 1996, n.9, pp. 1-2, 35-51. Disponível em: www.espacoacademico.com.br/schmeider.htm Acesso em 1/11/2006.

CRUZ, P; Universalizar: um desafio a ser vencido. Anuário Brasileiro da Educação Básica. Todos pela Educação, 2013.

CUNHA, L. A; Educação e desenvolvimento social no Brasil. São Paulo: Pioneiro, 1970.

FREIRE, P; Extensão ou comunicação? Rio de Janeiro: Paz e Terra, 1987.

MELLO, G. N. Educação e transição democrática - Ensino de $\mathbf{1}^{\mathbf{0}}$ Grau: as estratégias de transição democrática. São Paulo: Cortez, 1987.

PEREIRA, L. Rendimento e deficiência do Ensino Primário, em estudos sobre o Brasil Contemporâneo, São Paulo: Pioneira, 1971.

ROMANELli, O. O. História da Educação no Brasil: 1930/1973. 27. ed. Petrópolis: Vozes, 1978.

SANTOS, H. M. M. Olhar de Professor Face à Diversidade Cultural na Prática Escolar do Ensino Fundamental: um estudo de caso. 171folhas. Trabalho de Dissertação do Curso de Mestrado em Educação. Departamento de Ciências Sociais e Humanas da Universidade Lusófona de Humanidade e Tecnologia, Lisboa, 2008.

TEDESCO, J. C.O Novo pacto educativo: educação, competitividade e cidadania na sociedade moderna. São Paulo: Ática, 2001.

TORRES, R. M. Educação para todos: a tarefa por fazer: Porto Alegre Artimed. 2001.

UNESCO. Declaração Mundial sobre Educação para todos: satisfação das necessidades básicas de aprendizagem: Jomtien, 1990.

Declaração de Salamanca sobre princípios, políticas e práticas na área das necessidades educativas especiais. Conferência Mundial de Educação Especial. Salamanca, Espanha. 1994. 